\title{
Reminiscências da Antropofagia oswaldiana
}

\author{
Renato Xavier*
}

Resumo

O Manifesto Antropófago de 1928 é o mais radical manifesto cultural e político do início do século XX no Brasil. No contexto do movimento Modernista, Oswald Andrade lança mão, a partir da ideia de antropofagia, de uma visão crítica acerca da herança cultural ocidental, cuja oposição está diretamente relacionada à ideia de cópia da cultura estrangeira em detrimento da cultura nacional, o binômio cópia/original. No Manifesto de 1928, Oswald explora a noção antropofágica como metáfora para a transformação da cultura ocidental: deglutir o que vem de fora e transformar em algo totalmente novo; absorver o inimigo sacro; escapar às dicotomias nacional/estrangeiro, escola/floresta. A popularização da antropofagia oswaldiana só aconteceu a partir da década de 1950, reunindo o concretismo dos irmãos Campos, o Cinema Novo de Glauber Rocha e Joaquim Pedro de Andrade, o Teatro Oficina de José Celso Martins Corrêa, as artes plásticas de Hélio Oiticica, até desembocar finalmente no mais popular desses movimentos: a Tropicália de Caetano Veloso e Gilberto Gil. O objetivo deste artigo é explorar o pensamento antropofágico de Oswald de Andrade na cena artístico-cultural brasileira desde o Manifesto Antropofágico até o movimento Tropicalista, bem como levantar indícios do pensamento oswaldiano no debate político-cultural latino-americano da atualidade.

Palavras-chave: Antropofagia; Tropicália; Modernismo; Oswald de Andrade; Caetano Veloso.

\section{Abstract}

The Anthropophagic Manifesto of 1928 is the most radical cultural and political manifesto of the early twentieth century in Brazil. From the idea of anthropophagy, Oswald Andrade makes a critical analysis about the Western cultural heritage, whose opposition is directly related to the idea of copying foreign culture to the detriment of the national culture, the copy/original binomial. In the Manifesto, Oswald explores the anthropophagic notion as a metaphor for the transformation of Western culture: swallowing what comes from outside and transforming it into something totally new; absorb the sacred enemy; escape from the dichotomies national/foreign, school/forest. The popularization of Oswaldian anthropophagy only happened from the 1950s onwards, bringing together the concretism of the Campos brothers, Glauber Rocha's and Joaquim Pedro de Andrade's Cinema Novo, José Celso Martins Corrêa's Oficina Theater, the plastic arts of Hélio Oiticica, until finally ending up in the most popular of these movements: the Tropicália of Caetano Veloso and Gilberto Gil. The aim of this article is to explore the anthropophagic

\footnotetext{
Doutorando em Ciência Política pela Faculdade de Filosofia, Letras e Ciências Humanas da Universidade de São Paulo (FFLHC-USP), mestre em Relações Internacionais pelo programa Santiago Dantas (UNESP, UNICAMP e PUC-SP) e graduado em Relações Internacionais pela Universidade Federal de Santa Catarina (UFSC). E-mail: renatoxavier12@gmail.com.
} 
thinking of Oswald de Andrade in the Brazilian artistic and cultural scene from the Anthropophagic Manifesto to the Tropicalist Movement, as well as to show evidence of Oswaldian thought in the current Latin American political-cultural debate.

Keywords: Anthropophagy; Tropicália; Modernism; Oswald de Andrade; Caetano Veloso.

\section{Introdução}

Como legado do movimento Modernista, o "Manifesto da Poesia Pau Brasil”, de 1924, e o "Manifesto Antropófago", de 1928, ambos de Oswald de Andrade, fazem parte das manifestações mais características do movimento que teve início na Semana de Arte Moderna de 1922. O Manifesto da Poesia Pau Brasil guardava uma estética de equilíbrio entre o arcaico e o moderno. Por outro lado, o Antropófago era mais radical na ideia de subverter a lógica de produção cultural, social e política entre a ex-colônia e a metrópole. A despeito das nuances, ambos os manifestos procuravam trazer à tona a originalidade da cultura brasileira, sem perder de vista o olhar crítico acerca da herança cultural de tradição ocidental - mais especificamente a europeia (Nunes, 1972). O Manifesto de 1924 buscava ressaltar as vantagens comparativas do Brasil (uma poesia de exportação). O Antropófago, preocupado com a importação de ideias e instituições sem modificá-las, trazia à tona a noção de deglutir e transformar o que vem de fora em algo novo.

Tributários do movimento Modernista, os manifestos de Oswald de Andrade estavam inseridos em um contexto de profunda renovação literária. Conforme explora Antonio Candido (2008), o movimento Modernista, de forma geral, colocava à prova as novas aspirações intelectuais do período. A estrutura da cidade de São Paulo, no alvorecer do século XX, possibilitava a assimilação de formas divergentes. Nesse contexto, o grupo modernista surgiu em clara oposição ao "sistema literário solidamente constituído" (Candido, 2008, p. 170). Os modernistas tinham em mente e ideia de construir uma literatura oposta ao gosto da classe dominante, presente no Romantismo em São Paulo. Para Antonio Candido (2008, p. 171), não obstante os modernistas não apresentassem nenhum viés revolucionário, do ponto de vista político, as suas ideias representavam um esforço em transformar a literatura um "bem comum a todos". Nesse aspecto, os manifestos de Oswald de Andrade 
simbolizavam a união de classe ao incorporar o negro, o índio, os trabalhadores e a cultura popular como um todo.

O Brasil da segunda década do século XX era, portanto, um país assentado no patriotismo e no regime oligárquico. Oswald de Andrade responde a esse estado de coisas com o que Haroldo de Campos (1971) chama de poesia radical. A "poética da radicalidade" de Oswald está justamente no uso da linguagem e na consciência a partir dela: "A radicalidade da poesia oswaldiana se afere, portanto, no campo específico da linguagem, na medida em que esta poesia afeta, na raiz, aquela consciência prática, real, que é a linguagem (Campos, 1971, p. 10). Seja em Macunaíma de Mário de Andrade, ou no "Manifesto Antropófago" de Oswald de Andrade, a incorporação de aspectos da cultura popular à literatura nacional, em oposição à ordem burguesa tradicional, é uma das características mais fortes do movimento Modernista, e terá atenção especial no presente trabalho.

O Manifesto Antropófago tem no seu bojo a ideia de deglutir o que vem de fora. "Só a antropofagia nos une, socialmente, economicamente e filosoficamente" (Andrade, 1976). A partir da ideia de primitivismo, o elo entre as vanguardas europeias e as brasileiras, Oswald lança uma visão crítica acerca da herança cultural ocidental, uma inversão na relação de cópia do estrangeiro (Lima, 2016). No “Manifesto Antropófago", Oswald de Andrade explora o conceito de antropofagia cultural demonstrando que é possível assimilar ideias e modelos externos, no entanto, para devorá-los; deglutir o que vem de fora sem subordinações dicotômicas, as quais borbulhavam nas discussões da intelectualidade brasileira (Nunes, 1972). Segundo Silviano Santiago (2000, p. 14), a originalidade - o autor explanava sobre o lugar da América Latina na produção da cultura - "não se encontraria na cópia, mas sim na sua origem, apagado completamente pelos conquistadores", por esse motivo a crítica à América como simulacro da Europa. O bárbaro tecnizado devora seus inimigos e extrai deles o que há de melhor, um retorno às origens sem perder de vista as novas tecnologias (o futuro). Nas palavras de Oswald: "absorção do inimigo sacro. Para transformá-lo em totem" (Andrade, 1976). A intenção de Oswald é visível: deglutir a informação que vem de fora e devolver um produto novo, autenticamente brasileiro. Como pano de fundo, o Manifesto procura superar o sentimento de atraso. A 
antropofagia surge como metáfora para absorver e transformar os modelos culturais estrangeiros (Lima, 2016).

$\mathrm{O}$ ato de devorar o outro é, nesse sentido, uma forma de ressignificar as relações sociais e culturais. Ao apontar para esse caminho, Oswald escolhe combater os dualismos, misturando floresta com escola. Extrair o que há de melhor das vanguardas europeias pari pasu ao que há de mais rico na linguagem e cultura do povo brasileiro, um retorno da valorização do índio não catequizado. Por isso, o repúdio de Oswald às obras indianistas que exploravam um índio catequizado: "Contra o índio de tocheiro - e do negro na cultura brasileira. O índio filho de Maria, afilhado de Catarina de Médicis e genro de D. Antônio de Mariz" (Andrade, 1976). Em Oswald, a antropofagia é o método de se "ver com olhos livres", ou seja, ver o Brasil utópico, a matriz do instinto caraíba (Azevedo, 2012).

Muito restrita ao autor, a antropofagia só sai do ostracismo no final da década de 1950, quando ganha força com o movimento da Poesia Concreta (dos irmãos Campos). Ao empregar versos mais livres e uma crítica direta à política e à sociedade de consumo, as ideias do autor antropófago ganham novo impulso com o concretismo. Ao gosto oswaldiano, os poetas romperam com as tradições discursivas e subjetivistas da literatura brasileira (Naves, 2000). A partir disso, na década de 1960, o "Manifesto Antropófago" ganha nova roupagem com a explosão musical da Tropicália, em particular com Caetano Veloso e Gilberto Gil, a leitura do tropicalismo pelo crivo do Teatro Oficina de Zé Celso, ao Cinema Novo de Glauber Rocha, com o filme Terra em Transe, igualmente Joaquim Pedro de Andrade e a sua interpretação antropofágica de Macunaíma e às artes plásticas, com exposição no Rio de Janeiro de Hélio Oiticica: Tropicália. A popularização da antropofagia oswaldiana foi ainda maior na década de 1960, uma vez que não se restringiu ao campo da literatura. Seu pensamento tinha sido resgatado no teatro, no cinema, nas artes plásticas e na música.

Com força capaz de mobilizar massas a partir da rádio e da TV, o movimento Tropicalista teria como princípio libertar a música do nacionalismo e colocá-la em um patamar de experimentação, de devoração do externo. O que pretendiam os tropicalistas era produzir uma música nacional que extraísse o que tinha de melhor do passado, desde a Música Popular Brasileira (MPB) até a Bossa Nova. Contudo, sem 
negar as influências externas da guitarra de Jimi Hendrix e do grupo de Liverpool, os Beatles. A antropofagia oswaldiana servia como ideal aos tropicalistas, ainda que ressaltassem a diferença entre a experiência modernista dos anos 1920 e o movimento dos anos 1960. Nas palavras de Caetano Veloso:

\begin{abstract}
Nunca perdemos de vista, nem eu nem Gil, as diferenças entre a experiência modernista dos anos 20 e nossos embates televisivos fonomecânicos dos anos 60. [...] Desconfiei sempre do simplismo com que a ideia de antropofagia, por nós popularizada, tendeu a ser invocada (Veloso, 2017, p. 261).
\end{abstract}

O objetivo deste artigo é explorar brevemente o pensamento antropofágico de Oswald de Andrade na cena artístico-cultural brasileira, a partir do "Manifesto Antropofágico" até desembocar na Tropicália, bem como procurar indícios do pensamento oswaldiano no debate político-cultural atual na América Latina.

\title{
2. Antropofagia: a arte de devorar
}

Segundo Haroldo de Campos (2010), a antropofagia oswaldiana pode ser definida como um pensamento de devoração, ou seja, o ato de deglutir de forma crítica todo o legado cultural universal. Este ato, portanto, não consiste em submissão, ao contrário, traduz-se em transvaloração - na medida da crítica de Nietzsche ao passado e à memória. A antropofagia oswaldiana subverte a cultura europeia em solo americano. Nesta perspectiva, escritores brasileiros assumiriam a postura de retomada de sua cultura, abolindo as antigas heranças culturais, religiosas e literárias. Em outras palavras: deglutir as memórias do passado. "Contra a memória fonte do costume. A experiência pessoal renovada" (Andrade, 1976). Segundo a definição de Haroldo de Campos:

a antropofagia oswaldiana é o pensamento da devoração crítica do legado cultural universal, elaborado não a partir da perspectiva submissa e reconciliada do "bom selvagem" (idealizada sob o modelo das virtudes europeia no Romantismo brasileiro de tipo nativista, em Gonçalves Dias e José de Alencar, por exemplo), mas segundo o ponto de vista desabusado do "mau selvagem", devorador de brancos, antropófago. Ele não envolve uma submissão (uma catequese), mas uma transculturação: melhor ainda, uma "transvaloração": uma visão da história como função negativa (no 
sentido de Nietzsche), capaz tanto de apropriação como de expropriação, desierarquização, desconstrução (Campos, 2010, p. 234).

Devorar o que de melhor o inimigo tem proporciona uma renovação das suas próprias forças. Deglutir, portanto, é assimilar e [se] transformar em algo totalmente novo. O pensamento de Oswald inaugura a tradição de negar o velho saber de forma mecânica para, no entanto, absorvê-lo como em um processo dialético (Maltz, 1993). Oswald se serve de um mito poderoso: o canibalismo como ritual nas relações culturais. A antropofagia de Oswald de Andrade não significa um retorno ao estado arcaico, mas um resgate do homem enquanto primitivo socializado (bárbaro tecnizado), a harmonia entre cultura e natureza, floresta e escola. A antropofagia saiu em defesa de um experimentalismo, seja criticando a história do Brasil e seu passado colonial, seja estabelecendo uma saída utópica, traduzida na substituição do sistema patriarcal burguês pelo matriarcado da comunidade primitiva. Para Augusto de Campos (2015) "a Antropofagia, entendida em termos oswaldianos, tem o significado de uma assimilação cultural seguida de uma reelaboração criativa, como os poetas concretos a interpretaram".

Benedito Nunes (1972) sugere a devoração de Oswald como símbolo de um processo antropofágico simultâneo: metáfora, diagnóstica e terapêutica. Para o autor, a metáfora seria orgânica, uma vez que se inspira nos índios tupinambás com os primeiros colonizadores do Brasil, cuja vitória no combate acarretava em devorar seus inimigos. Do ponto de vista da cultura brasileira, o ato de deglutir teria suscitado relação intrínseca com nosso passado colonizado, à condição de repressão imposta pela ação colonizadora. Postos os diagnósticos da colonização e repressão, a devoração seria a prática de aliviar as violações sofridas, ou seja, um ato terapêutico. Como resultado da violência sistemática, política e social, os hábitos intelectuais e as manifestações literárias e artísticas teriam produzido um trauma repressivo.

A proposta de Oswald não nega que a cultura europeia está na base da formação da cultura brasileira. Nessa perspectiva, ao se apropriar da cultura do Outro, ao devorá-lo, o "Manifesto Antropófago" procura operar o mesmo princípio de violência do colonizador. Ao contrário da violência física, a deglutição para Oswald é cultural, sua linguagem contém um caráter metafórico. O ritual exagerado do ato antropofágico tem uma natureza de dessacralização, ritual pagão de devorar o Outro a 
fim de assimilá-lo (Candido e Silvestre, 2016). O debate em torno da antropofagia oswaldiana é extenso e, portanto, extrapolaria este parco espaço. Ainda assim, faz-se relevante apontar alguns termos desse debate e seus principais críticos. A dicotomia entre o que é ou não próprio da nossa cultura orienta boa parte das discussões sobre a construção da identidade nacional na primeira metade do século XX. Oswald de Andrade não escapa a isso. Sua antropofagia é senão a radicalização da polarização entre o próprio e o alheio, entre América e Europa.

Na esteira do debate sobre a dependência cultural, Roberto Schwarz - um dos principais críticos - afirmou que os manifestos de Oswald de Andrade eram na verdade "uma interpretação triunfalista sobre nosso atraso". À luz da célebre frase está a crítica da estrutura social brasileira. Segundo Schwarz (2009b), nosso sentimento de "civilização postiça" não está na imitação, mas sim no processo capitalista dos países periféricos. Para o autor, a cópia não é problemática per se, seria possível reaproveitar elementos da cultura europeia: "A questão da cópia não é falsa, desde que tratada pragmaticamente, de um ponto de vista estético e político, e liberta da mitológica exigência da criação a partir do nada" (Schwarz, 2009b, p. 136). A crítica de Schwarz à poética oswaldiana se assemelha à crítica que o autor fez ao Modernismo brasileiro. Segundo Schwarz (1989), o movimento Modernista não alterou o processo histórico de dependência. Sua crítica é bastante relevante ao apontar os limites da cultura na superação do abismo material (entre centro e periferia). Segundo o autor (1999, p. 10), o triunfo do Modernismo, especialmente do ponto de vista da sua ampla divulgação nos meios de comunicação, tem menos a ver com a superação de problemas históricos e mais com a "sua integração ao discurso da modernização conservadora". A ideia de mudar a condição do Brasil de país esquecido para um "exportador" de cultura própria esbarrou, segundo Schwarz (1989), nas mesmas questões que Oswald buscava positivar. Ainda assim, o autor reconhece a importância dos elementos alegóricos manipulados por Oswald, em particular a questão Brasil burguês versus Brasil colônia, uma dualidade que desembocou mais tarde no tropicalismo na década de 1960 e influenciou a literatura nacional.

Silviano Santiago (2000), em seu ensaio O Entre-lugar no discurso latinoamericano, vislumbra a devoração crítica da cultura estrangeira e aposta no hibridismo 
entre cópia e original: o latino-americano vive entre "a assimilação do modelo original - entre o amor e o respeito pelo já escrito - e a necessidade de se produzir um novo texto que afronte o primeiro e muitas vezes o negue" (2000, p. 26). Neste jogo (entre prisão e transgressão, submissão e obediência) "se realiza o ritual antropófago da literatura latino-americana" (Santiago, 2000, p. 26). Atravessado por polêmicas e rico em debate, o radical "Manifesto Antropófago" de Oswald de Andrade seguiu sendo alvo de controvérsia. A partir dos anos 1950, quiçá, devorado e transformado em algo completamente novo.

\section{A cena artístico-cultura da Antropofagia}

No final da década de 1950, a música nacional começava a tomar nova forma com elementos da cultura brasileira. Foi a Bossa Nova que forneceu à Música Popular Brasileira (MPB) um teor nacionalista (abandono da bateria em troca da percussão). A nova estrutura rítmica nasce em 1958 e João Gilberto era o principal expoente. Como os poetas concretos, João Gilberto se empenhou em romper com as tradições, pautando sua música pela rejeição dos sambas-canções (Naves, 2000, p. 35). Segundo Santuza Cambraia Naves (2000), a figura de João Gilberto nos círculos da poesia concreta se tornou recorrente. Naves (2000) resgata Tom Jobim como um dos precursores da Bossa Nova, tão relevante para o novo movimento musical brasileiro quanto João Gilberto. Segundo o autor:

\footnotetext{
O estilo bossa-nova não se exaure com a estética de João Gilberto, mostrando-se, pelo menos do ponto de vista de músicos ligados a esta tendência, bastante diversificado. Recorro, a título de exemplo, à figura de Tom Jobim. Se ninguém tem dúvidas quanto à influência de João Gilberto sobre Tom, pelo menos no momento inicial da bossa nova, não se pode esquecer, no entanto, que este compositor havia começado a sua carreira musical num momento anterior às inovações do final dos anos 50 (Naves, 2000. p. 37).
}

A Bossa Nova se empenhou na valorização de elementos (imagens e sons) da natureza brasileira. Por sua beleza própria, a cidade do Rio de Janeiro foi palco de 
inspiração para o movimento musical. Mostrar a beleza da cidade a partir da música contribuiu para imprimir à Bossa Nova um caráter de exportação (Campos, 1974). Segundo Caetano Veloso (2017, p. 262), João Gilberto criou um estilo singular para a música popular brasileira, absorvendo as influências externas e transformando-as em algo totalmente novo: "era um exemplo claro de atitude antropofágica". João Gilberto criou um estilo pessoal, mas não personalista, de música: os ritmos e elementos tradicionais da música popular brasileira somados à influência da música norteamericana, por exemplo, o Jazz, dão suporte à fala de Caetano Veloso. Dessa deglutição, criou-se uma música de exportação tipicamente brasileira (Campos, 1974).

A antropofagia oswaldiana retornava à baila a partir de algumas posturas defendidas pelo concretismo, ainda no final dos anos 1950, ganhando grande visibilidade nas décadas seguintes. A antropofagia passou a ocupar um espaço significativo na produção artística do período. Desde a poesia, com Torquato Neto e Waly Salomão, ao cinema de Nélson Pereira dos Santos, Glauber Rocha e Joaquim Pedro de Andrade, até as artes plásticas de Glauco Rodrigues, Lygia Clark e Hélio Oiticica, a antropofagia se renovava. O teatro, grande inspirador da tropicália, também resgatou Oswald no Teatro Oficina.

Em 1958 os poetas e irmãos Haroldo e Augusto de Campos, juntamente com Décio Pignatari, lançaram o movimento de vanguarda literária. A proposta essencial era questionar a poesia tradicional, suas métricas e rimas. Radicalizava-se, assim, a antropofagia oswaldiana na poesia brasileira:

poesia concreta: produto de uma evolução crítica de formas dando por encerrado o ciclo histórico do verso (unidade rítmico-formal), a poesia concreta começa por tomar conhecimento do espaço gráfico como agente estrutura. espaço qualificado: estrutura espácio-temporal, em vez de desenvolvimento meramente temporístico-linear, daí a importância da idéia de ideograma, desde o seu sentido geral de sintaxe espacial ou visual, até o seu sentido específico (fenollosa/pound) de método de compor baseado na justaposição direta - analógica, não lógico-discursiva - de elementos. "il faut que notre intelligence s'habitue à comprendre synthéticoideographiquement au lieu de anlytico-discursivement" (apollinaire). eisenstein: ideograma e montagem (Campos, Campos e Pignatari, 1956, s.p.).

O Manifesto da Poesia Concreta era a tensão de palavras-coisas no espaço. Em seu Manifesto, publicado originalmente na revista ad-arquitetura, em 1956, Augusto de Campos vê a palavra em si mesma como um instrumento à disposição para ser 
usado. Tributários de Oswald de Andrade, os concretistas se somaram à geleia geral que viria a ser a Tropicália.

Nas artes plásticas, Oswald também era rememorado nas décadas de 1950 e 1960. Apostava-se na emoção e na desvalorização da arte em si como procedimento de crítica, cujo intuito era desmistificar a arte: uma crítica à intelectualidade do período e um apelo à arte como fonte de comunicação de massa. As artes plásticas de Hélio Oiticica, uma das maiores referências do período, visavam à criação particular de arte brasileira, abandonando imitações de procedimentos de grandes centros internacionais, uma forma de fugir do binarismo vanguardismo versus nacionalismo:

\begin{abstract}
Nem pedagogia conteudista (base da arte de esquerda), nem elevação do gosto médio do público (utopia presente nas vanguardas construtivistas, como a Poesia Concreta; que defendiam a aproximação da arte e da linguagem não para desvalorizar a instituição-arte mas para valorizar e incrementar a percepção do mundo, por parte do homem moderno) (Napolitano e Villaça, 1998, s.p).
\end{abstract}

A montagem da peça O Rei da Vela (1967), que vale ressaltar não é uma peça antropofágica de Oswald, mas sim uma leitura antropofagicizada de Zé Celso, também teve grande impacto no laboratório do que seria o tropicalismo musical dos anos seguinte. Nos elementos de estética oswaldiana, o "mau-gosto", como forma de polêmica, era traço característico da peça e do estilo de dirigir de Zé Celso. A estética do "mau-gosto" ficaria mais tarde evidenciada em Chacrinha - ícone da TV brasileira (e reivindicado como peça chave do tropicalismo). Ao assumir a estética do "mau-gosto", - Teatro Oficina buscou resistir aos padrões da crítica, em particular da esquerda nacionalista, denunciando a sociedade brasileira como "teatralizada", isto é, desconectada dos problemas reais e da nossa história.

A partir das ideias oswaldiana, o teatro de Zé Celso procurou sublinhar um Brasil desigual, injusto, não como resultado da relação de força com as potencias externas, mas através da soma de fatores externos e internos (Napolitano e Villaça, 1998). A peça do Teatro Oficina empregou uma linguagem que consagrava a ideia de um movimento de vanguarda. Um movimento que operava nas bases sociais, políticas e comportamentais dos jovens daquele período. 0 2o ato do Rei da Vela (Frente Única Sexual) unia elementos de agressão, estética e comportamento, um procedimento que se viu ainda mais evidente na vanguarda tropicalista. A inversão de valores do que é 
belo e feio exibia o caráter debochado da linguagem oswaldiana. Dar voz à linguagem e à estética das classes não dominantes era um dos artifícios utilizado por Oswald em sua poética radical.

O espetáculo O Rei da Vela foi dedicado a Glauber Rocha, diretor do Filme Terra em Transe. A obra de 1967 teve grande impacto na intelectualidade da época. O teatro de Zé Celso e o Cinema Novo agiriam em Caetano Veloso de forma irreversível. A forma como o Movimento Tropicalista leu a obra oswaldiana está intimamente ligada ao Teatro Oficina. A compreensão da antropofagia a partir do Teatro é uma marca importante do período e merece destaque. A forma teatral e a música popular dos baianos explodiram com força no fim da década de 1960

\footnotetext{
As polêmicas em torno da radicalização da proposta de agressividade do Grupo Oficina, potencializadas na peça Roda Viva (que estreou em janeiro de 1968) tornaram público o debate em torno das "novidades" surgidas, sobretudo na música e no teatro. Neste momento, as polêmicas começam a apontar para a idéia de que aquilo tudo poderia se traduzir num movimento (Napolitano e Villaça, 1998).
}

Assim, a estética do Brasil nos anos 1960 tinha como uma das principais inovações o confronto dicotômico entre o bom e o mau (gosto) entre o belo e o feio. O resgate de Oswald no cenário cultural culminou na Tropicália, reinventada nas criações teatrais e no cinema. Os movimentos culturais daquele período retratavam os conflitos no seio da sociedade brasileira (Santos, 1990). Nesse contexto, o movimento Tropicalista surge na cena artístico-cultura brasileira. A combinação entre cinema, teatro, poesia e artes imprimiu uma visão crítica das contradições presentes no processo de modernização da sociedade brasileira. Restava a Gilberto Gil e a Caetano Veloso forjar os elementos culturais em disputa em forma de música.

\section{Tropicália ou neoantropofagismo}

"O movimento tropicalista já nasceu sob o signo desse elo, um
neoantropofagismo, segundo Caetano Veloso" (Rolnik, 1997, s.p).

Na esteira da efervescente década de 1960, a Tropicália surge ao sabor das inquietações da década a partir da noção de antropofagia oswaldiana da década de 1920, mais especificamente no seu Manifesto Antropófago de 1928. O tropicalismo 
representou um momento de convergência com as vanguardas artísticas da época. 0 cinema, o teatro, as artes plásticas e a poesia foram ingredientes na composição do Movimento Tropicalista a partir de 1967 e Caetano Veloso reconhece tais influências:

Se o tropicalismo se deveu em alguma medida a meus atos e minhas ideias, temos que considerar como deflagrador do movimento o impacto que teve sobre mim o filme Terra em transe, de Glauber Rocha. [...]. Meu coração disparou na cena de abertura, quando, ao som do mesmo cântico de candomblé que já estava na trilha sonora de Barravento, [...] se vê, numa tomada aérea do mar, aproximar-se a costa brasileira. $E$, à medida que o filme seguia em frente, as imagens de grande força que se sucediam, confirmavam a impressão de que aspectos inconscientes de nossa realidade estavam à beira de se revelar (Veloso, 2017, p. 123).

Encabeçada por Caetano Veloso e Gilberto Gil ${ }^{1}$, a Tropicália apareceu como forte crítica ao cenário político, particularmente ao golpe militar de 1964, não na forma de canção-protesto, mas uma posição contrária aos valores morais e ideológicos do período. Com a música Domingo no Parque, Gilberto Gil assumia a sua busca pelo som universal, uma estética de aproximação com a música pop internacional (Napolitano e Villaça, 1998). Em 1968, um ano após estourar a música de Gil, Caetano Lança Alegria, Alegria que dá amplitude ao Movimento (em um contexto de festivais de música na televisão). Os novos meios de comunicação de massa, TV e Rádio, serviam para irradiar movimentos. Era inevitável que o universal se misturasse com o nacional, ainda que se pregasse o contrário (Campos, 1974).

A benevolência com o que vinha de fora era combatida pelos nacionalistas, os quais viam nos tropicalistas a simpatia com a interferência da cultura externa no país. A influência da guitarra elétrica e a sonoridade das batidas eletrônicas encobria o que o movimento de fato buscava: a informação nova, a música pop, uma mistura com outros ritmos nacionais. Gil e Caetano exploravam uma forma de arte que a população pudesse consumir, sem restrições, como coloca Campos:

Numa entrevista a Dirceu Soares, Gilberto Gil procurou definir a nova linha das suas composições e das de Caetano como "musica pop". A expressão é discutível, porque a pop-art já tem uma semântica definida, no quadro das artes plásticas, e poderia supor uma dependência que, realmente, não existe, embora haja algumas afinidades. Mas a explicação de Gil demonstra que ele sabe muito bem o que quer. Vale a pena repeti-la: "Música pop - diz

\footnotetext{
${ }^{1}$ Refere-se a Gil e Caetano sem prejuízo dos demais tropicalistas, como, Torquato Neto, Gal Costa, Tom Zé e outros.
} 
ele - é a música que se consegue comunicar de maneira tão simples, como um cartaz de rua, um outdoor, um sinal de trânsito, uma história em quadrinhos" (Campos, 1974, p. 155).

Com isso, Caetano e Gil procuravam demonstrar que a música produzida no Brasil podia conter elementos da nossa cultura e manter a autenticidade mesmo bebendo de fontes ocidentais. Com o movimento colocado no cenário artístico-cultural brasileiro, Gil e Caetano contribuíam para a música e, igualmente, para o debate sobre a cultura brasileira. O movimento estreava a fase provocadora da esquerda, uma forma de tratar os embates tradicionais no campo da política e da arte (Holanda e Gonçalves, 1982; Favaretto, 1996; Santiago, 2000). Assim, a Tropicália contestava as premissas da esquerda tradicional.

A arte dos tropicalistas tinha um caráter de transformação, a música servia como instrumento para dar luz à realidade brasileira. Ao contrário dos tropicalistas, a arte para a esquerda tradicional não continha a "realidade do povo", além do seu teor subjetivo, a arte era vista como forma de alienação. A esquerda da década de 1960 via no imperialismo o principal entreve para a revolução brasileira. Portanto, a guitarra tropicalista soava incômoda para a esquerda daquele período (Coelho, 1989, p. 161). Do ponto de vista dos tropicalistas, a realidade brasileira era muito mais complexa: uma mistura do nacional com o internacional. Não havia, nesse sentido, traços de pureza na cultural nacional. O internacional, assim como o nacional, o arcaico e o novo eram elementos presentes e constitutivos da identidade nacional (Coelho, 1989). Os atritos da sociedade brasileira em sua procura por uma identidade e a diferenciação do Outro a esta altura fervilhavam. As canções Alegria, Alegria e Domingo no Parque evidenciavam os conflitos. A mistura de elementos cultos com sons do cotidiano, a exemplo do uso do berimbau, davam um pouco do tom do que era o movimento Tropicalista de inspiração oswaldiana. O rótulo de tropicalistas - aceito por Caetano e Gil - criou um fato novo na cena da indústria musical incipiente no Brasil (Silva, 1990).

A música Tropicália, do primeiro álbum do movimento, o disco Tropicália ou Panis et Circencis, trazia um tom irônico. Em um momento político de polarização, o movimento Tropicalista assumia uma postura contrária à militância, mas não menos contundente. $\mathrm{O}$ estilo de estética cafona dos tropicalistas tinha como intenção mostrar 
um caráter desengajado, ainda que a música mostrasse sua força por si. Como pano de fundo, os tropicalistas evitavam se misturar aos nacionalistas ou aos conservadores:

Ao assimilar a chamada "música cafona", o Tropicalismo - com a sofisticação de arranjos de incontestáveis músicos do quilate de Rogério Duprat - trouxe para o Brasil a desconstrução do pensamento provinciano de que há simplificadores limites dicotômicos na música; e, portanto, na política e na compreensão cultural do Brasil (Ribeiro, 2007, p. 58).

Na perspectiva de Lidia Santos (1990), o Tropicalismo, ampliamdo na cena musical, trouxe à tona a os impasses da esquerda brasileira pós-golpe de 1964 . Segundo a autora "calcado no populismo, esse modelo se erigira numa exaltação dos valores nacionais, que estariam presentes nas camadas populares. A obra de arte, para ser autêntica, deveria espelhar-se nessas classes e a elas dirigir-se" (Santos, 1990, p.116). O movimento tinha como oposição exatamente o nacionalismo da esquerda hegemônica da década de 1960. O tom adotado nas letras era de um país continental, da valorização da América Latina, uma cultura capaz de assimilar influências externas, visando assim o continente maior

\begin{abstract}
A esse nacionalismo, o Tropicalismo opunha, além dos elementos citados, uma noção continental da cultura brasileira. Composições como Soy loco por ti, America, de CAPINAM e Gilberto GIL, ao utilizarem a mistura de português e espanhol na sua letra, enquanto utilizam a rumba como ritmo e o gingado caribenho como interpretação, não deixam dúvida quanto à latino-americanidade da cultura brasileira presente em suas propostas. Note-se que a Revolução Cubana e a guerrilha, já citada na letra de Alegria, alegria, começa a crescer no Brasil e avança, à mesma época, em toda a América Latina (Silva, 1990, p. 117).
\end{abstract}

Silviano Santiago (1988), por sua vez, faz uma distinção entre o otimismo da produção literária e cultural antes do golpe de 1964 - característica de boa parte dos intelectuais à época - e a alegria da cultura trazida pelos tropicalistas. O otimismo animado pelo desejo de desenvolvimento social não foi interrompido com o golpe militar. Não se via na cultura brasileira um pessimismo capaz de congelar a criatividade artístico-cultural daqueles anos, ao contrário, foi no horror do golpe militar que nasceu uma reação contra a censura e a repressão. Para Cristopher Dunn (2009), a irrupção retratada por Silviano Santiago dava indícios de uma contracultura no seio da juventude brasileira - não imune aos movimentos do século XX. 
No auge da agitação cultural, os baianos conseguiram radicalizar na música o que Oswald de Andrade procurou fazer na poética. Os elementos da antropofagia oswaldiana estavam presentes desde a forma de se vestir até a dança agressiva. Esses elementos expunham o caráter vanguardista dos baianos tropicalistas. Signos e linguagens que demonstravam o caráter devorador do movimento. A Tropicália propôs fusão entre o sacro e o profano e, assim como João Gilberto, Caetano Veloso conduzia a música popular brasileira ao lado das principais vanguardas culturais estrangeiras (Campos, 1974).

O bárbaro tecnizado é reivindicado por Caetano. Como parte importante no pensamento de Oswald em seus manifestos, o índio é recuperado no espaço alegórico da cultura brasileira dos tropicalistas. Ao negar o subdesenvolvimento como algo limitador da nossa cultura, Caetano se aproxima de Oswald com a seguinte frase: "nego-me a folclorizar o meu subdesenvolvimento para compensar as dificuldades técnicas" (Campos, 1974, p. 212). Como Oswald de Andrade, o movimento Tropicalista sofreu forte oposição. Uma das mais significativas partiu de Roberto Schwarz. Ao contrário dos que viam na contracultura proposta pelos tropicalistas como uma espécie de panaceia, o movimento tinha sido revivido por forças sociais e culturais conservadoras, fruto do golpe militar de 1964. Uma modernidade que resultaria na internacionalização da economia brasileira - maléfica desse ponto de vista. Caetano Veloso e Roberto Schwarz protagonizaram décadas depois debates calorosos. Dunn (1999) comenta que, para Schwarz (2009a), a identidade nacional brasileira era ativada (pelos tropicalistas) por uma ideia de Brasil atemporal, cujas contradições históricas eram vistas como emblemas indenitários. Em outras palavras,

Para Schwarz a alegoria tropicalista era ativada por meio da sujeição de um inventário de emblemas culturais e arcaicos ou anacrônicos à "luz branca do ultra-moderno". Schwarz admitia que em suas manifestações mais irônicas a Tropicália conseguia "reter a figura mais íntima e dura das contradições da produção intelectual presente", mas também advertia que ela representava o Brasil como um absurdo. Por absurdo ele entendia que os tropicalistas propunham uma "idéia atemporal de Brasil" na qual suas contradições históricas eram apresentadas como emblemas de identidade nacional."Tropicália", canção-manifesto de Caetano Veloso, apresentada em seu primeiro álbum solo de 1968 , era igualmente um ponto de referência para a interpretação de Schwarz (Dunn, 2009, p. 116). 
Muitos autores reafirmam a potência existente no tropicalismo como motor de transformação cultural. Interessa a este texto enfatizar, quando assim for evidenciado, o poder que Oswald de Andrade teve sobre o principal movimento cultural brasileiro da segunda metade do século XX. Tomar posicionamentos políticos difíceis naquele período só podia ocorrer quando se tinha no polemista Oswald uma inspiração. Por este motivo, Augusto de Campos (1974) vê no tropicalismo características da antropofagia de Oswald. A música dos tropicalistas expressava, ademais, a inquietação de uma cultura de raízes fortes, mas com o olhar no que há de melhor no mundo a ser devorado. O trecho abaixo, de Campos, explica que

Significativo é, por outro lado, o entusiasmo que Oswald de Andrade Suscitou em Caetano Veloso: "Atualmente eu componho, depois de ter visto O Rei da Vela. O espetáculo é a coisa mais importante que vi". Oswald foi o inimigo $\mathrm{n}$ o 1 do nacionalismo ufanista, fechado e fanfarrão. Não se enganem com a poesia Pau-Brasil. É a primeira História Nova do Brasil. Uma AntiHistória. Ao invés do nacionalismo tacanho e autocomplacente, um nacionalismo crítico e antropofágico, aberto a todas as nacionalidades, deglutidor-redutor das mais novas linguagens da tecnologia moderna (Campos, 1974, p. 161).

O modo metaforizado de ser brasileiro e o diagnóstico de que é preciso deglutir para criar algo novo foi recriado pelos tropicalistas com impactos significativos na cena artístico-cultural brasileira do século $X X$, com reverberações até os tempos atuais. 0 diálogo travado por esses artistas ressaltou a história da significação e ressignificação da nossa identidade. A resposta da Tropicália ao modelo nacional-popular de seus contemporâneos é concomitante à retomada da tradição internacionalista da antropofagia - um diálogo sempre aberto e passível de novas interpretações (Santos, 1990). Para Coelho (1989), se a sociedade se alimentava do externo, os tropicalistas não poderiam abrir mão dessa fonte. O forte contato entre o arcaico e o moderno era traço da sociedade brasileira. Deglutir e transformar em algo novo um ato antropofágico desde Oswald até os tropicalistas.

\section{Considerações finais: Antropofagia e Caliban}

O impacto do Manifesto Antropofágico (1928) na cultura brasileira foi exposto mais ou menos neste breve artigo. Nesta seção, a ideia é encontrar e pontuar alguns 
vestígios da antropofagia no pensamento político latino-americano atual. Por óbvio, esta tarefa não se esgota neste artigo, uma vez que se trata de uma pesquisa de maior fôlego. Nas últimas décadas, alguns escritores leram a antropofagia de Oswald na perspectiva de Caliban, personagem de William Shakespeare na peça A Tempestade. Vale ressaltar que desde o século XIX autores latino-americanos trabalharam à exaustão Caliban, destaco: José Martí, José Rodó, Dario Rubén, Paul Groussac e outros.

Escritores latino-americanos não se furtaram de tratar da antropofagia de Oswald de Andrade à luz das semelhanças e diferenças com o personagem de William Shakespeare, Caliban. Roberto Fernandez Retamar (1999), depois de muitos anos escrevendo sobre Caliban, discorre sobre a possível aproximação entre Caliban e a antropofagia de Oswald. Para o autor (1999), a primeira questão que causa estranheza é o fato de que em toda a obra de Oswald de Andrade não haver citação de Caliban, ainda que Oswald fosse assíduo leitor das obras de William Shakespeare. Nesse aspecto, Retamar (2004) nota a ausência e comenta:

¿Antropofagia hoy? Si ello implica preguntarse por la vigencia de lo mejor del pensamiento de Oswald de Andrade en este orden, es menester decir que, a través de sus deslumbramientos, contradicciones y cambios, todavía tiene mucho que enseñarnos el fantasioso y peleador "Quijote gordo", como lo llamó su amigo Candido. En las primeras líneas dije que no creía que «Caliban» (es decir, el tema de que trata) hubiese perdido vigencia. Con no menos razón debo decir algo similar de la Antropofagia oswaldiana, que de la devoración incorporativa de su primera salida, cuando exaltó con jubilosa ferocidad nuestro mundo inmediato, fue a parar a un audaz planteo utópico de regreso de la humanidad a lo más noble del pasado, habiéndose alimentado de los logros de la historia. Todo, con el aliento de un poeta que creía en sus imágenes con fuerza y valor (Retamar, 2004, p. 49).

Nas últimas décadas, Caliban e o antropófago seguiram caminhos distintos. Não obstante, aumentaram os estudos que procuram demonstrar aproximação entre o personagem de Shakespeare e a antropofagia de Oswald de Andrade. Parte desse debate ainda se desenvolve na exploração das diferenças de vanguarda e algumas questões ainda precisam ser respondidas: qual a fonte dos modernistas antropófagos? Qual a relação com as fontes dos autores latino-americanos que trabalhavam com as personagens da peça de William Shakespeare? (Sartori, 2009).

Em seu livro Canibalia: canibalismo, calibanismo, antropofagia cultural y consumo en América Latina (2008), Carlos Jáuregui resgata a antropofagia de Oswald de Andrade e Caliban no contexto de consumo na era da globalização. Na obra de 
Jáuregui, o consumo cultural é descrito como um processo similar entre Caliban e a antropofagia, no entanto, a razão comunicativa escapa das definições elitistas da cultura, tanto quanto as identidades desenhadas pelo colonialismo e o neocolonialismo latino-americano. Nesse sentido, a cultura de consumo seria

\begin{abstract}
donde su tropo homónimo, capitalismo y consumismo, conllevan la visión de este último como práctica cultural afín al mercado capitalista, conforme la lógica de un cierto canibalismo tardío (parafraseando a F. Jameson), en una lectura también perversa y excéntrica, como es la que postula Jáuregui para el devenir de nuestra América canibal (Hernandéz, 2008).
\end{abstract}

A questão se Caliban é ou não antropófago foi respondida por Jáuregui da seguinte forma: “En la era del caníbal surge Calibán, y en la era de Calibán re-emerge el caníbal", si bien "No hay entre ellos un relevo propiamente dicho sino una superposición palimpséstica [...] sino que aparecen como segmentos entretejidos por la historia". Isto posto, Caliban e a antropofagia de Oswald podem ser palimpsestos, algo que é diversas vezes reescrito em diversos contextos históricos, não havendo assim hierarquização do novo sobre o velho e sim uma recriação constante (Azevedo, 2012). Encontrar pontos de convergência em Caliban e na noção de antropofagia de Oswald requer mais fôlego de pesquisa. Procurou-se demonstrar, contudo, que há um campo de investigação em aberto.

Este trabalho procurou mostrar em que medida o Manifesto Antropófago de Oswald de Andrade é uma das mais singulares contribuições do movimento Modernista à cultura brasileira. Muitos autores procuraram dar luz às ideias de Oswald no intuito de manter sua influência. Não obstante o ostracismo da antropofagia, Oswald volta à tona com a força do Movimento da Poesia Concreta no fim da década de 1950. Com uma linguagem que fugia às regras do tradicional, os concretistas resgataram o pensamento polêmico e radical de Oswald e influenciaram diretamente o que viria a ser mais tarde a Tropicália.

O cinema, o teatro, a poesia e as artes plásticas consubstanciaram o movimento tropicalista do fim da década de 1960. A Tropicália musical se deparou com uma massa urbana ligada ao rádio e à televisão, uma juventude desejosa por cultura, consumidora de novas influências internas e externas. Na busca por uma cultura que devorasse o que vem de fora para transformar em algo novo, a Tropicália 
colocou a antropofagia no centro do debate político-cultural do Brasil. É possível afirmar que, a partir da Tropicália, a antropofagia de Oswald de Andrade ganhou um novo status, seja na recuperação da arte e da poesia antropofágica no cenário cultural, seja nas rodas de debates acadêmicos sobre a formação da identidade latinoamericana.

\section{Referências bibliográficas}

ANDRADE, O. 1976. "O manifesto antropófago". In: TELES, G. M. Vanguarda européia e modernismo brasileiro: apresentação e crítica dos principais manifestos vanguardistas. $3^{a}$ ed. Petrópolis: Vozes; Brasília: INL.

AZEVEDO, B. 2012. Antropofagia: palimpsesto selvagem. Dissertação (Mestrado em Teoria Literária e Literatura Comparada) - Faculdade de Filosofia, Letras e Ciências Humanas, Universidade de São Paulo. São Paulo, 2012. Disponível em: $<$ http://www.teses.usp.br/teses/disponiveis/8/8151/tde-04082016-165033/>. Acesso em: 2018-06-19.

CAMPOS, A. 1974. Balanço da Bossa e outras bossas. Ed. Perspectiva: São Paulo. 2.a edição.

CAMPOS, A; CAMPOS, H e PIGNATARI, D. 2018. "Poesia Concreta: um manifesto. Augusto de Campos". Uol, São Paulo. Publicado Originalmente na Revista ad-arquitetura e decoração, $\mathrm{n}$. 20, São Paulo, Nov/dez. 1956. Disponível em: < http://www2.uol.com.br/augustodecampos/poesiaconc.htm>. Acesso em: jun. 2018.

. 2015 "Antes e depois - uma entrevista com Augusto de Campos". São Paulo, 13 de dezembro de 2015. Entrevista concedida a Rodolfo Viana. Ilustríssima, Folha de São Paulo. Disponível em https://www1.folha.uol.com.br/ilustrissima/2015/12/1717866-antes-e-depois--uma-entrevista-com-augusto-de-campos.shtml. Acesso em: abril de 2018.

CAMPOS, H. 1972. Uma poética da radicalidade. In: ANDRADE, O. Obras completas vol. 7: Poesias reunidas. Rio de Janeiro: Civilização brasileira, 1972.

- 2010. "Da razão antropofágica: diálogo e diferença na cultura brasileira". In:_._Metalinguagem e Outras Metas: ensaios de teoria e crítica. 4. ed. São Paulo: Perspectiva, p. 231-255.

CANDIDO, A. 1990. "Radicalismos". Estudos avançados, São Paulo, v.4, n.8, p.418, Abril. Disponível em: http://www.scielo.br/scielo.php?script=sci arttext\&pid=S0103$40141990000100002 \& \operatorname{lng}=e n \& n r m=i s o$. Acesso em jul. 2018.

. 2008. Literatura e sociedade: estudos de teoria e história literária. Rio de Janeiro: Ouro sobre azul. 
CANDIDO, W e SILVESTRE, N. 2016. O discurso da antropofagia como estratégia de construção da identidade cultural brasileira. Revista Acta Scientiarum. Language and Culture. Maringá, v. 38, n. 3, p. 243-251, July-Sept., 2016.

COELHO, C. 1989. "A Tropicália: cultura e política nos anos 1960". Tempo Social; Rev. Sociol. USP, São Paulo, 1 (2), 2. sem. 1989. Disponível em: http://www.scielo.br/pdf/ts/v1n2/01032070-ts-01-02-0159.pdf. Acesso em: jun. 2018.

DUNN, C. 2009. Brutalidade jardim: a Tropicália e o surgimento da contracultura brasileira. São Paulo: Editora UNESP.

FAVARETTO, C. 1996. Tropicália: alegria, alegoria. 2ª ed. São Paulo, Ateliê Editorial.

HERNANDEZ, B. e CARLOS, J. 2008. "Canibalia. Canibalismo, calibanismo, antropofagia cultural y consumo en América Latina. Ensayos de Teoría Cultural". Estud. filol., Valdivia, n. 43, p. 223232 .

em: https://scielo.conicyt.cl/scielo.php?script=sci arttext\&pid=S007117132008000100018\&lng=pt \&nrm=iso. Acesso em jul de 2018.

HOLANDA, H. B. e GONÇALVES, M. 1982. Cultura e participação nos anos 60. São Paulo: Brasiliense.

JÁUREGUI, C. 2008. Canibalia. Canibalismo, calibanismo, antropofagia cultural y consumo en América Latina. Ensayos de Teoría Cultural, Madrid: Iberoamericana. 724 pp. Vol. I.

LIMA, B. C. 2016. "Eles devoraram tudo: primitivismo, barbárie e as vanguardas". Revista do Instituto de Estudos Brasileiros. USP, n. 64. Disponível em: http://www.scielo.br/pdf/rieb/n64/0020-3874-rieb-64-0296.pdf. Acesso em jul. 2018.

MALTZ, B. 1993. "Antropofagia: rito, metáfora e pau-brasil". In: FERREIRA, S.; MALTZ, B.; TEIXEIRA, J. (Orgs.) Antropofagia e tropicalismo. Porto Alegre: Editora da UFRGS.

NAPOLITANO, M. e VILLACA, M. M. 1998. "Tropicalismo: As Relíquias do Brasil em Debate". Rev. bras. Hist., São Paulo, v.18, n.35, p.53-75. Disponível em: http://www.scielo.br/scielo.php?script=sci arttext\&pid=S010201881998000100003\&lng=en\& nrm=iso. Acesso em julho de 2018.

NAVES, S. C. 2000. "Da bossa nova à tropicália: contenção e excesso na música popular". Rev. bras. Ci. Soc., v.15, n.43, p.35-44. Disponível em: http://www.scielo.br/pdf/rbcsoc/v15n43/003.pdf. Acesso em: abril 2018.

NUNES, B. 1972. "Antropofagia ao alcance de todos". In.: ANDRADE, O. Obras Completas. vi. Do Pau-Brasil à Antropofagia e às utopias. Rio de Janeiro: Civilização Brasileira.

RETAMAR, F. 2004. Todo Caliban. Buenos Aires: CLACSO.

RIBEIRO, J. E. L. 2007. Viva Iracema, viva Ipanema: o tropicalismo (ouvido) à luz do dilema latino-americano. Dissertação apresentada ao Programa de Pós-Graduação em Letras do Centro de Ciências Humanas e Naturais da Universidade Federal do Espírito Santo, como requisito parcial para obtenção do Grau de Mestre em Estudos Literários. Disponível em: 
http://repositorio.ufes.br/bitstream/10/3197/1/tese 1971 Jorge\%20Evandro\%20Lemos\%20Ri beiro.pdf. Acesso em maio de 2018.

ROLNIK, S. 1997. "Uma ideia que continua se realizando". Folha de São Paulo. Ilustrada. São Paulo, 5 de novembro de 1997. Disponível em: https://www1.folha.uol.com.br/fsp/1997/11/05/ilustrada/6.html. Acesso em: jun. 2018.

SANTOS, L. 1990. "A cafonice vai ao paraíso: a arte da tropicália e os primeiros romances de Manuel Puig". Revista Letras. Curitiba. N. 39. p. 115-134. Disponível em: http://dx.doi.org/10.5380/rel.v39i0.19161. Acesso em Jun. de 2018.

SANTIAGO, S. 1988. "Poder e Alegria: A literatura brasleira pós-64-reflexões". In.: Nas malhas da letra. São Paulo: Companhia das Letras. Janeiro.

2000. Uma literatura nos trópicos. Ensaio sobre dependência cultura. Ed. Rocco: Rio de

SARTORI, R. 2009. "Comunicación intercultural, antropofagia y la canibalización de caliban en américa latina". Revista Científica de Información y Comunicación. 6, pp265-282. Disponível em: http://www.icjournal-ojs.org/index.php/IC-Journal/article/viewFile/199/196. Acesso em jun de 2018.

SCHWARZ, R. 1987. "A carroça, o bonde e o poeta modernista". In: .Que horas são? Ensaios. São Paulo: Companhia das Letras, 1987. p. 11-28.

. 2009a. "Nacional por subtração". In SCHWARZ, R. (Org.), Cultura e Política. São Paulo: Paz e Terra.

. 2009b. "As ideias fora do lugar". In R. Schwarz (Org.), Cultura e Política. São Paulo, SP: Paz e Terra.

TEIXEIRA, J. 1993. (Orgs.) Antropofagia e tropicalismo. Porto Alegre: Editora da UFRGS.

VELOSO, C. 2017. Verdade Tropical. 3a Ed. São Paulo: Companhia das Letras.

Tramitação do artigo na revista Submetido: 14/09/2018

Revisões requeridas: 03/01/2019

Versão revista: 12/02/2019

Aceito: 07/03/2019 